\title{
Subclinical visuospatial impairment in Parkinson's disease: the role of basal ganglia and limbic system
}

\author{
Stefano Caproni ${ }^{1}$, Marco Muti ${ }^{2}$, Antonio Di Renzo ${ }^{2}$, Massimo Principi ${ }^{3}$, Nevia Caputo ${ }^{3}$, Paolo Calabresi ${ }^{1,4}$ \\ and Nicola Tambasco ${ }^{1}$ *
}

${ }^{1}$ Clinica Neurologica, Azienda Ospedaliera - Università di Perugia, Italy

2 Servizio di Fisica Sanitaria, Azienda Ospedaliera di Terni, Italy

${ }^{3}$ Servizio di Neuroradiologia, Azienda Ospedaliera di Terni, Italy

${ }^{4}$ I.R.C.C.S. - Fondazione S. Lucia - Roma, Italy

\section{Edited by:}

Jaime Kulisevsky, Sant Pau

Hospital - Sant Pau Institute of

Biomedical Research, Spain

\section{Reviewed by:}

William Hutchison, University Health

Network, Canada

Francesca Morgante, University of

Messina, Italy

*Correspondence:

Nicola Tambasco, Clinica Neurologica,

Azienda Ospedaliera - Università di

Perugia, S. Andrea delle Fratte, 06156

Perugia, Italy

e-mail:n.tambasco@libero.it
Background: Visual perception deficits are a recurrent manifestation in Parkinson's disease (PD). Recently, structural abnormalities of fronto-parietal areas and subcortical regions, implicated in visual stimuli analysis, have been observed in PD patients with cognitive decline and visual hallucinations. The aim of the present study was to investigate the salient aspects of visual perception in cognitively unimpaired PD patients.

Methods: Eleven right-handed non-demented right-sided onset PD patients without visuospatial impairment or hallucinations and 11 healthy controls were studied with functional magnetic resonance imaging while performing a specific visuoperceptual/visuospatial paradigm that allowed to highlight the specific process underlying visuospatial judgment.

Results: Significant changes in both cortical areas and subcortical regions involved in visual stimuli processing were observed. In particular, PD patients showed a reduced activation for the right insula, left putamen, bilateral caudate, and right hippocampus, as well as an over-activation of the right dorso-lateral prefrontal and of the posterior parietal cortices, particularly in the right hemisphere.

Conclusions: We found that both loss of efficiency and compensatory mechanisms occur in PD patients, providing further insight into the pathophysiological role of the functional alterations of basal ganglia and limbic structures in the impairment of visuoperceptual and visuospatial functions observed in PD.

Keywords: Parkinson's disease, fMRI, visuospatial/cognitive impairment, hippocampus, insula

\section{INTRODUCTION}

Cognitive impairment is common in Parkinson's disease (PD), even in the early stages, affecting around $25 \%$ of patients without dementia at the time of the diagnosis (1). Cognitive changes are mainly characterized by executive, memory, and visual perception deficits (2).

In PD patients, visuospatial deficits have been identified using tests of line orientation, memory for spatial location, and mental rotation. Furthermore, impairment in visuoperceptual abilities has been observed in object detection, categorization of visual stimuli, and face recognition (3). It has been hypothesized that these alterations play a role in the mechanisms of pivotal motor signs of the disease, such as freezing of gait $(4,5)$, and are connected to the development of visual hallucinations $(1,6)$. Recent findings have also suggested a role for lateralization of the basal ganglia circuits in stimuli perception, which determines different clinical manifestation in left- and right-side PD onset (7).

Over the last few years, visual perception and its underlying mechanisms have been investigated in PD, with increasing interest in the relationship between cognitive abilities and structural neuroradiological substrates $(2,8-10)$. However, only few studies have taken into account functional cortical activation of areas and networks involved in the visual perception processes, especially in the early stages of PD. Thus, this study aimed to detect brain activation during a specific visuoperceptual/visuospatial task in cognitively unimpaired PD patients, compared to healthy controls, using functional magnetic resonance imaging (fMRI), in order to investigate the salient aspects of the subclinical impairment of the visual perception network.

\section{MATERIALS AND METHODS \\ PATIENTS}

Eleven right-handed non-demented right-sided onset PD patients ( 8 males, 3 females; mean age: 65 years, range: 59-75), mean disease duration $3.8 \pm$ standard deviation 1.5 years [mean Unified Parkinson's Disease Rating Scale (UPDRS) off-state: $20 \pm 4.5$; mean Hoehn and Yahr scale (11): 2, range 1-3; mean Mini-Mental State Examination (12): $27.1 \pm 1.4$ ], all treated with levodopa (mean dose: $500 \pm 100 \mathrm{mg}$ daily) were recruited. Inclusion criteria were: clinical diagnosis of PD according to the United Kingdom Parkinson's Disease Society Brain Bank criteria (13); no evidence of dementia according to both DSM-IV criteria and clinical diagnostic criteria for dementia associated with PD, published by Emre et al. in 2007 (particularly with normal attention, executive, and 
visuospatial features) (14); the absence of hallucinations; no evidence of depression symptoms at the assessment using the Beck Depression Inventory (15); no significant vascular damage, no brain tumors, no marked cortical, and/or subcortical atrophy on MRI scan; no use of anxiolytics, antidepressants, or antipsychotics, which could potentially affect cerebral blood flow; an optimal motor performance and no excessive movement artifacts during fMRI.

Eleven healthy right-handed age and sex-matched subjects served as controls. None of the control subjects had past or present neurological, cardiovascular, or psychiatric diseases. All participants gave their written informed consent to the study, which was approved by the local Ethics Committee (Umbria CEAS), according to the principles expressed in the Declaration of Helsinki. Complete demographic characteristics of the PD patients and controls are listed in Table $\mathbf{1 .}$

\section{VISUOPERCEPTUAL/VISUOSPATIAL TASK}

The subjects laid in the scanner and could read the instructions displayed on a white panel placed in the front of the scanner. A right-sided keyboard was connected to the magnetic resonance console to enable the observers to monitor the whole test. All subjects performed a structured paradigm organized according to a classic block design having two conditions. Abstract geometric meaningless images were used for both tasks. In the visuoperceptual task (VP), a sequence of diverse single figures were projected on the panel, and the subjects were asked to press the key with the index finger when a previously defined image appeared (Figure 1). This target image was definitely different from all the others, in order to minimize the memory and visuospatial effort. In the visuospatial task (VS), a sequence of coupled figures were projected, which were identical or partially different (orientation, lack of a piece, partial filling, ...). The subjects had to press the key when coupled figures were different (Figure 1). The subjects were instructed to practice both tasks just before the fMRI scanning, to avoid over-training and mnemonic learning of the image sequences. All exams were performed at the same hour (3:00 or 4:00 p.m., in off-state, at least $12 \mathrm{~h}$ after the last administration of L-dopa). Data acquisition for the entire paradigm was obtained during a single MRI.

\section{MRI DATA ACOUISITION}

In this study, a $1.5 \mathrm{~T}$ Philips scanner was used, equipped with whole-brain single-shot 3D blood oxygen level dependent echoplanar imaging (EPI) hardware. Head pads and a firm chin strap immobilized head flexion-extension. Thirty-four axial slices of $4 \mathrm{~mm}$ thickness, parallel to the intercommisural plane (from $z=-50 \mathrm{~mm}$ to $z=+80 \mathrm{~mm}$ ), were collected using an EPI gradient echo sequence: echo time $=50 \mathrm{~ms}$; repetition time $(\mathrm{TR})=3000 \mathrm{~ms}$; flip angle $=90^{\circ}$; field of view $=230 \mathrm{~mm}$; voxel size $=3.59 \times 3.59 \times 4 \mathrm{~mm}^{3}$; matrix $=64 \times 64$. T1-weighted images were also acquired. Data acquisition was organized in an epoch-related design. Acquisition time was divided into VP periods followed by VS periods. Each period consisted of seven EPI acquisitions of $3000 \mathrm{~ms}$ (TR) each, $21 \mathrm{~s}$ in total. For both VP and VS, the image's projection lasted for a whole EPI acquisition (3000 ms), resulting in seven images per epoch. The two exercises
Table 1 | Clinical and demographic characteristics of patients and control subjects.

\begin{tabular}{|c|c|c|c|c|c|c|c|}
\hline & Sex & Age & $\begin{array}{l}\text { PD } \\
\text { duration }\end{array}$ & $\begin{array}{l}\text { Hohen } \\
\text { and } \\
\text { Yahr }\end{array}$ & $\begin{array}{l}\text { UPDRS } \\
\text { off-state }\end{array}$ & MMSE & $\begin{array}{l}\text { LEDD } \\
\text { (mg) }\end{array}$ \\
\hline \multicolumn{8}{|c|}{ PD PATIENTS } \\
\hline 1 & m & 59 & 3 & 1.5 & 14 & 28 & 450 \\
\hline 2 & $\mathrm{~m}$ & 75 & 3 & 2 & 19 & 27 & 450 \\
\hline 3 & $\mathrm{~m}$ & 58 & 2 & 1 & 19 & 30 & 450 \\
\hline 4 & $\mathrm{~m}$ & 64 & 3 & 2 & 19 & 27 & 450 \\
\hline 5 & $\mathrm{~m}$ & 64 & 5 & 2 & 14 & 28 & 500 \\
\hline 6 & $\mathrm{~m}$ & 65 & 5 & 2.5 & 25 & 26 & 500 \\
\hline 7 & $\mathrm{~m}$ & 67 & 4 & 2 & 24 & 26 & 500 \\
\hline 8 & $\mathrm{~m}$ & 69 & 5 & 3 & 30 & 26 & 500 \\
\hline 9 & $f$ & 60 & 5 & 2 & 18 & 27 & 500 \\
\hline 10 & $f$ & 65 & 2 & 1 & 8 & 28 & 400 \\
\hline 11 & $f$ & 69 & 5 & 3 & 30 & 25 & 800 \\
\hline Mean & & 65 & 3.8 & 2 & 20 & 27.1 & 500 \\
\hline \multicolumn{8}{|c|}{ CONTROLS } \\
\hline 1 & f & 60 & & & & & \\
\hline 2 & $\mathrm{~m}$ & 76 & & & & & \\
\hline 3 & $f$ & 56 & & & & & \\
\hline 4 & $\mathrm{~m}$ & 68 & & & & & \\
\hline 5 & $\mathrm{~m}$ & 63 & & & & & \\
\hline 6 & $\mathrm{~m}$ & 63 & & & & & \\
\hline 7 & $\mathrm{~m}$ & 66 & & & & & \\
\hline 8 & $\mathrm{~m}$ & 71 & & & & & \\
\hline 9 & $\mathrm{~m}$ & 59 & & & & & \\
\hline 10 & $\mathrm{~m}$ & 64 & & & & & \\
\hline 11 & $f$ & 70 & & & & & \\
\hline Mean & & 65.1 & & & & & \\
\hline
\end{tabular}

UPDRS, Unified Parkinson's Disease Rating Scale; MMSE, Mini-Mental State Examination; LEDD: Levodopa equivalent daily dose.

were performed for 8 periods, for a total of 16 periods, divided into 112 volumes. Tasks lasted $336 \mathrm{~s}$, corresponding to $5 \mathrm{~min}$ and $36 \mathrm{~s}$. Potential brain abnormalities were previously excluded by examining conventional FLAIR, T2-weighted, and T1-weighted images.

\section{MRI ANALYSIS}

Functional magnetic resonance imaging data were analyzed using SPM5 (Statistical Parametric Mapping, Wellcome Department of Cognitive Neurology, London, UK) (16). The functional images were co-registered and realigned to the first volume to correct for head translation or rotation during the scanning and to avoid incorrect spatial coordinates of activated voxels. Images were also normalized, using a standard voxel size $2 \times 2 \times 2 \mathrm{~mm}^{3}$, to the stereotaxic space of Talairach and Tournoux (17) using the threedimensional volume (18). Images were also spatially smoothed with a Gaussian kernel of $8 \mathrm{~mm}$ full-width half maximum and temporally smoothed with a Gaussian kernel (FWHM=8s) (19). Statistical analysis of the activations obtained during the performance of tasks was based upon an epoch-related experimental design. The data obtained were modeled with a hemodynamic 


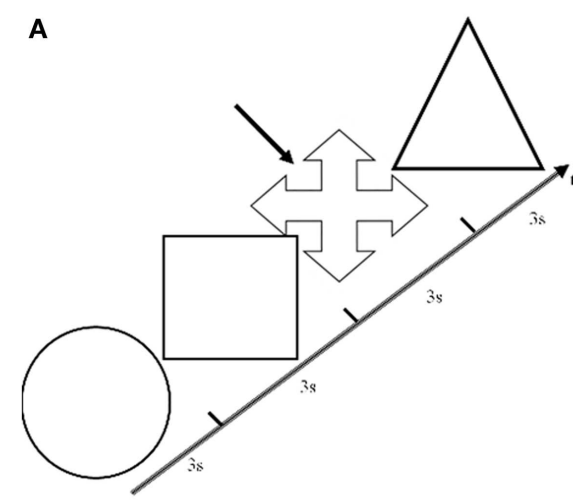

FIGURE 1 | Visuoperceptual and visuospatial tasks. (A) An example of a figure sequence presented in the visuoperceptual task. Subjects were asked to press the key when the target image indicated by the arrow appeared. (B) An example of a figure
B

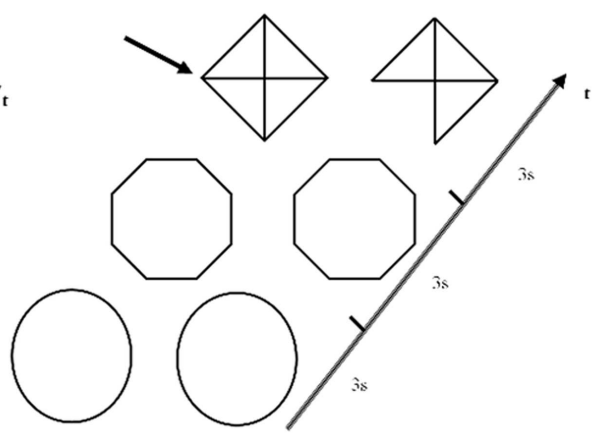

sequence presented in the visuospatial task. Subjects were asked to press the key when coupled figures resulted different (as indicated by the arrow). For both tasks, seven slices lasting $3 \mathrm{~s}$ were presented during each epoch. response function having an impulsive local flux variation. The sum of hemodynamic variations during an active period allowed for the calculation of a mean cortical activation during an exercise performance, obtained by applying the General Linear Model, $y=(\beta / \beta e r r)^{\star} x+c(16)$. Therein, the whole-brain mean activation signal corresponding to VS was compared to VP, by performing a first-level fixed-effect analysis having a cluster threshold of 10 voxels with $p<0.001$ for all subjects. Group data were obtained through a random-effect second-level analysis using the SPM5 software package and were used to calculate a betweengroup analysis. The second-level analysis provided results on overactivations of whole-brain cortical areas and subcortical regions, with intensity measured by $F$-score. In summary, the final contrast revealed: $\mathrm{PD}$ patients $(\mathrm{VS}>\mathrm{VP}$ ) versus Controls $(\mathrm{VS}>\mathrm{VP})$.

\section{RESULTS}

\section{BEHAVIORAL RESULTS}

All subjects correctly carried out both tasks. Both PD patients and control subjects made a similar number of errors for both tasks that did not differ significantly $(p>0.05)$. None of the subjects performed any visible movements other than those required by the tasks.

\section{fMRI RESULTS}

Compared to controls, for the second-level between-group comparison VS $>$ VP PD patients had an over-activation of the right dorso-lateral prefrontal cortex (DLPFC), defined as the sum of part of Broadman areas 9 and 46, and bilateral posterior parietal cortex (PPC), defined as the sum of Broadman areas 7 and 40 (particularly in the right hemisphere) (Figure 2, Table 2). Whereas, controls had a greater activation of the right insula, left putamen, bilateral caudate (particularly in the head), and right hippocampus (Figure 3, Table 2).

\section{DISCUSSION}

This is the first fMRI study investigating specific subclinical VS/VP aspects in cognitively unimpaired PD patients without

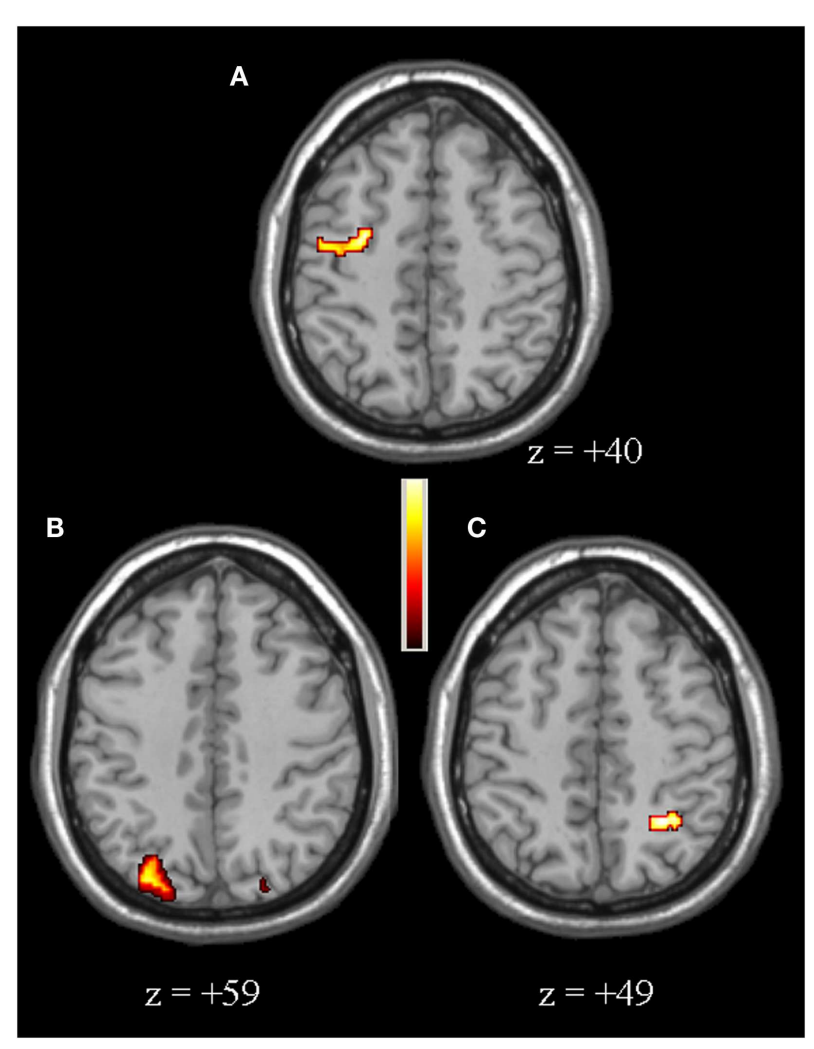

FIGURE 2 | [PD patients (VS > VP)] > [Controls (VS > VP)]. The

over-activations of right dorso-lateral-prefrontal cortex (A), right (B), and left (C) posterior parietal cortex observed in patients, compared to controls, for the second-level analysis VS $>$ VP are shown. Colors bar range for $F$-score: 2-17.95.

hallucinations, providing evidence on the functional activity associated with visual perception in PD.

In this study, we used a specific paradigm that allowed us to differentiate the most important functions of visual perception in the 
Table 2 | VS $>$ VP second-level analysis results

\begin{tabular}{llrrrr}
\hline Comparison & Area & \multicolumn{3}{c}{ Coordinates $(\mathbf{m m})$} & \multirow{2}{*}{$\boldsymbol{F}$-score } \\
\cline { 3 - 5 } & & $\boldsymbol{x}$ & $\boldsymbol{y}$ & $\boldsymbol{z}$ & \\
\hline PD $>$ Controls & R DLPFC & -38 & 7 & 40 & 17.95 \\
& L PPC & 32 & -59 & 49 & 12.51 \\
& R PPC & -19 & -69 & 59 & 14.75 \\
Controls $>$ PD & R insula & -34 & -14 & 20 & 12.20 \\
& L putamen & 20 & 10 & 6 & 16.78 \\
& L caudate & 14 & 22 & 6 & 11.83 \\
& R caudate & -18 & 24 & 6 & 16.67 \\
& R hippocampus & -35 & -15 & -13 & 14.26 \\
\hline
\end{tabular}

For each region, Talairach coordinates and F-scores of the local maxima are reported ( $p<0.001)$. DLPFC: dorso-lateral prefrontal cortex; L: left; PPC: posterior parietal cortex; PD: Parkinson's disease; R: right.

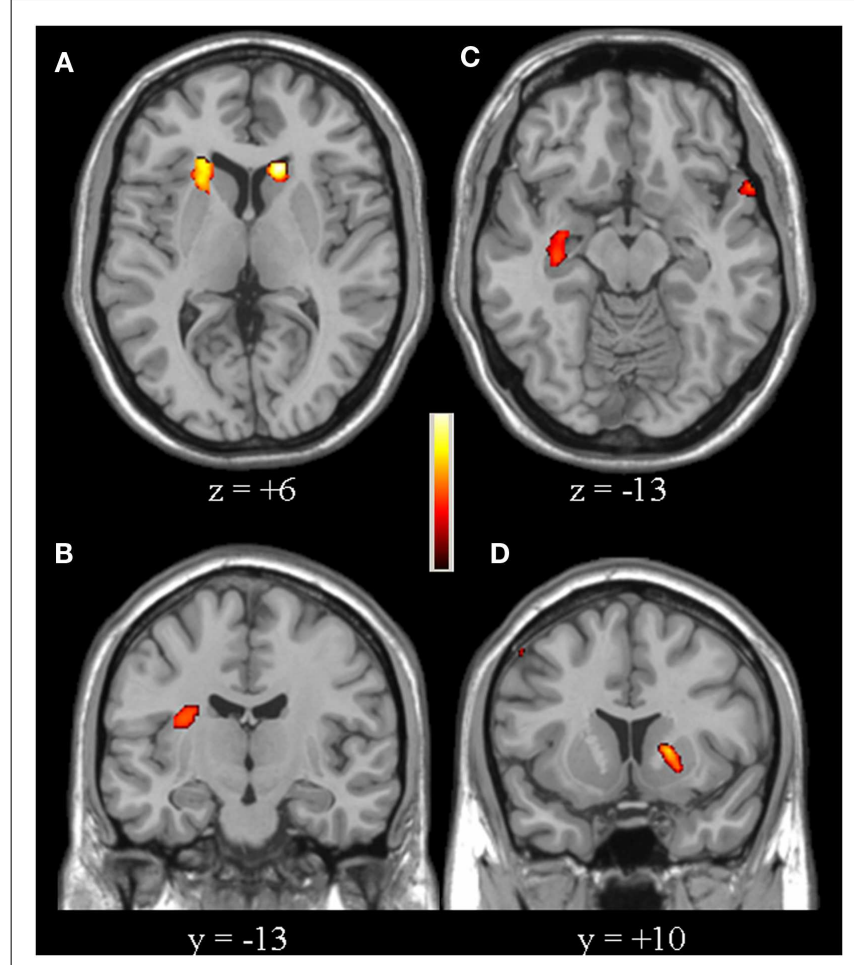

FIGURE 3 | [Controls (VS > VP)] > [PD patients (VS > VP)]. The

over-activations of bilateral caudate (A), right insula (B), right hippocampus (C), and left putamen (D) observed in controls, compared to patients, for the second-level analysis VS $>$ VP are shown. Colors bar range for $F$-score: 2-16.78.

same fMRI exam. Visual perception is divided into two functionally and neuroanatomically distinct systems: the visuoperceptual or "what" system, encoded by the "ventral" occipito-temporal pathway, and the visuospatial or "where" system, encoded by the "dorsal" occipito-parietal pathway (20).

In our paradigm, while VP represented a basic visual perceptual task $(21,22)$, VS combined both the skill to find the objects' differences $(21,23)$ as well as the competence regarding line orientation and shape judgment $(21,24)$. Therefore, the comparison VS $>$ VP allowed for the subtraction of visual stimulation, visuoperceptual analysis, and motor response, with aim to highlight the specific process underlying visuospatial judgment.

Our study shows that PD patients had a reduced activation of the right insula, left putamen, bilateral caudate (in particular in right hemisphere), and right hippocampus, compared to controls. Recent neuroimaging studies have highlighted the importance of various connections among these regions, specifically nigralinsular (25) and striatal-insular (26) connections, that are part of basal ganglia networks involved in attention and cognitive functions (27).

Our finding regarding the putamen can be interpreted on the pathophysiological basis of PD (28), according to the right-sided onset of disease in our patients. Similarly, the pivotal role of caudate in cognitive functions (29), in particular visual perception process (30), has been confirmed. The bilateral defect in caudate activation in PD patients is in agreement with recent findings on the right hemispheric dominance for visual perception. Moreover, results on the impairment of this region suggest its role in deciding ambiguous contexts (31).

The hypo-activation of the right insula is one of the most interesting findings of our study. Insula has been found to be involved in cognitive functions of PD patients (10), particularly in the presence of hallucinations (32). In addition, this region is presumed to play a salient role in attentional and complex processing in healthy subjects (33) and is characterized by long-range functional interactions with visual perception networks (34). Accordingly, the activation of the right insula in our healthy controls could denote a "switch" between attentional and visuospatial networks provoked by specific VS > VP comparison (35), while the relative hypo-activation in PD patients may suggest the initial loss of efficiency, anticipating the development of cognitive impairment and visual hallucincations.

Our finding that the right hippocampus in PD patients is less activated, compared to controls, confirms the involvement of this region in cognitive features in $\mathrm{PD}(1,3,31,36,37)$. It is known that hippocampus contributes to allocentric frame of reference, as part of the "Top-Down" visual processing system, that is minimally impaired in PD from previous studies (38). Recent studies have also pointed out a specific role for the right hippocampus in processing and storage of spatial information, encoded by neocortical-hippocampal loop in healthy subjects $(39,40)$. Thus, although deficits in hippocampal activation in PD have been usually considered as reduced efficiency in executive and attentional functions, our results, due to the specificity of the paradigm, suggest an association between the hippocampus and subclinical visuospatial dysfunction in $\mathrm{PD}$, but might also be due to levodopa.

PD patients showed greater activations of right DLPFC and bilateral PPC, compared to controls. Both of these regions, together with frontal-striatal circuits, are known to be part of the "Top-Down" visual processing system, which is involved in the selection and organization of complex visual information (41). In particular, DLPFC and PPC specifically contribute to egocentric frame of reference, which was reported to be impaired in $\mathrm{PD}$ patients showing visual perceptual deficits in previous 
studies $(38,42)$. Moreover, both regions are part of a visual perception network detected as developmental shift from frontalcingulate-striatal network in young adulthood (43). Thus, the over-activation observed in PD patients compared to age-matched controls could be considered a consequence of a neurodegenerative process underlying $\mathrm{PD}$, but might also be due to levodopa.

Regarding the DLPFC alone, it has been hypothesized that it has a role in executive abilities and its involvement has been observed in PD patients with cognitive impairment (44), even in the nondemented stage (1). A reduction of DLPFC activation in PD patients has usually been attributed to altered striatal-frontal projections (45), but based on recent findings not in agreement with the traditional model, an underlying deficient interplay between the nigrostrial and mesocortical dopamine system has been suggested (46). Furthermore, a resting state fMRI study reported a parcelation of DLPFC in different subregions that mark a transition to visuospatial/sensorimotor networks (47). Accordingly, an event-related fMRI study evidenced subregions of DLPFC selectively encoding for positive and negative visual spatial priming (48). Our DLPFC greater activation could be considered compensatory in PD patients, through a continuous control performed by the “Top-Down" visual processing system, which was observed to be linked to visual working memory (49). We observed a similar response in $\mathrm{PD}$ patients learning of a novel complex motor task (50). This latter observation could be consistent with the suggested difficulty of PD patients to use sensory information for planning and executing complex or new tasks (51).

Several studies on healthy subjects have demonstrated that bilateral PPC is specialized in visual discrimination and localization $(52,53)$. Although the right dominance of parietal cortex for visual perceptual abilities has been confirmed (54), recent neuroimaging studies have suggested new interesting roles for the left parietal cortex, including alerting attention (55), memory retrieval (56), and multisensory visual-tactile integration through a "TopDown" system $(7,57)$. Moreover, a compensatory activation of left PPC, in the case of reduced activity of right PPC after transcranial magnetic stimulation, has been recently observed (58). Being so, right PPC is thought to share dynamic connections with bi-hemispheric remote regions during exogenously cued visuospatial attention (59). PPC has also been reported to be part of the basal ganglia circuits, given that diverse evidence regarding nigro-parietal and striatal-parietal connections has been recently reported $(7,25,26)$.

In our study, $\mathrm{PD}$ patients showed a greater activation of bilateral PPC, with a right predominance, compared to controls. This result has not been previously reported, except for a comparison between PD patients without hallucinations versus PD patients with hallucinations (60). Our finding can be explained by the specificity of the task performed and by the clinical aspects of our patients. In fact, all PD patients presented a short duration of disease, in absence of cognitive impairment and hallucinations, and, notably, were right-handed with right-sided onset of disease. It has been suggested that right-sided onset PD is characterized by impairment in local level processing of visual perception information, due to left frontal and parietal hemispheric deficits, which can be antagonized by the attentional network. Conversely, left-sided onset PD is characterized by abnormal global level processing of visual perception information, due to right parietal deficit, under all conditions $(7,30)$. Since our PD patients performed the tasks with the same accuracy of controls, we hypothesize that the greater activation of bilateral PPC could be necessary to overcome the initial impairment of the network. In particular, the relatively lesser signal in left PPC, ipsilateral to the onset of neuropathological process, could represent an incomplete compensatory activity for executive processing (45).

Our study had a number of limitations. First, because of the limited number of enrolled subjects and the magnetic field strength, the activation of some areas, such as the cerebellum, thalamus, and subthalamic nucleus (61), may not have been detected. Similarly, a functional connectivity mapping was not performed. It is possible that for this reason we were unable to detect the activation of the inferior frontal junction area and the precuneus, which are part of cognitive networks involving all areas and regions listed in our findings $(62,63)$. Finally, since PD patients were not tested in the $\mathrm{ON}$ drug condition, we did not perform the $\mathrm{ON}$ versus OFF comparison, which might yield changes specifically related to striatal dopamine depletion. It should be investigated in future studies.

\section{CONCLUSION}

Our study analyzed the brain activations involved in salient aspects of visual perception in PD patients. Our findings suggest that the basal ganglia and limbic structure defects have a determining role in subclinical visuoperceptual and visuospatial impairments. Further investigations are needed to determine the roles of side of onset, disease duration, treatment, and exhaustive cognitive profile in the pathophysiology of visuospatial functioning in PD.

\section{ACKNOWLEDGMENTS}

The authors would like to thank the technical and nursing team of the Radiodiagnostic Department at "S. Maria" Hospital in Terni. Disclosure Statement: Nicola Tambasco has received funding for travel and speaker from Novartis, Lundbeck, and Boheringer Ingelheim; Paolo Calabresi receives research support from Bayer Schering, Biogen, Boehringer Ingelheim, Eisai, Novartis, Lundbeck, Sanofi-Aventis, Sigma-Tau, and UCB Pharma; and from Ricerca Corrente IRCCS, Ricerca Finalizzata IRCCS (European Community Grants SYNSCAFF and REPLACES), the Italian Minister of Health and Agenzia Italiana del Farmaco (AIFA); Stefano Caproni, Marco Muti, Antonio Di Renzo, Massimo Principi, and Nevia Caputo declare no conflicts of interest. The study was approved by the local Ethics Committee (Umbria CEAS), according to the principles expressed in the Declaration of Helsinki.

\section{REFERENCES}

1. Barone P, Aarsland D, Burn D, Emre M, Kulisevsky J, Weintraub D. Cognitive impairment in nondemented Parkinson's disease. Mov Disord (2011) 26:2483-95. doi:10.1002/mds.23919

2. Emre M. Dementia associated with Parkinson's disease. Lancet Neurol (2003) 2:229-37. doi:10.1016/S1474-4422(03)00351-X

3. Pereira JB, Junqué C, Martí MJ, Ramirez-Ruiz B, Bargalló N, Tolosa E. Neuroanatomical substrate of visuospatial and visuoperceptual impairment in Parkinson's disease. Mov Disord (2009) 24:1193-9. doi:10.1002/mds.22560

4. Domellöf ME, Elgh E, Forsgren L. The relation between cognition and motor dysfunction in drug-naive newly diagnosed patients with Parkinson's disease. Mov Disord (2011) 26:2183-9. doi:10.1002/mds.23814 
5. Nantel J, McDonald JC, Tan S, Bronte-Stewart H. Deficits in visuospatial processing contribute to quantitative measures of freezing of gait in Parkinson's disease. Neuroscience (2012) 221:151-6. doi:10.1016/j.neuroscience.2012.07.007

6. Ramirez-Ruiz B, Junque C, Marti MJ, Valldeoriola F, Tolosa E. Cognitive changes in Parkinson's disease patients with visual hallucinations. Dement Geriatr Cogn Disord (2007) 23:281-8. doi:10.1159/000100850

7. Schendan HE, Amick MM, Cronin-Golomb A. Role of a lateralized parietalbasal ganglia circuit in hierarchical pattern perception: evidence from Parkinson's disease. Behav Neurosci (2009) 123:125-36. doi:10.1037/a0013734

8. Ibarretxe-Bilbao N, Tolosa E, Junque C, Marti MJ. MRI and cognitive impairment in Parkinson's disease. Mov Disord (2009) 24(Suppl 2):S748-53. doi:10. $1002 / \mathrm{mds} .22670$

9. Ibarretxe-Bilbao N, Junque C, Marti MJ, Tolosa E. Brain structural MRI correlates of cognitive dysfunctions in Parkinson's disease. J Neurol Sci (2011) 310:70-4. doi:10.1016/j.jns.2011.07.054

10. Silbert LC, Kaye J. Neuroimaging and cognition in Parkinson's disease dementia. Brain Pathol (2010) 20:646-53. doi:10.1111/j.1750-3639.2009.00368.x

11. Hohen MM, Yahr MD. Parkinsonism: onset, progression and mortality. Neurology (1967) 17:427-42. doi:10.1212/WNL.17.5.427

12. Folstein MF, Folstein SE, McHugh PR. "Mini Mental State". A practical method for grading the cognitive state of patients for the clinician. J Psychiatr Res (1975) 12:189-98.

13. Reichmann H. Clinical criteria for the diagnosis of Parkinson's disease. Neurodegener Dis (2010) 7:284-90. doi:10.1159/000314478

14. Emre M, Aarsland D, Brown R, Burn DJ, Duyckaerts C, Mizuno Y, et al. Clinical diagnostic criteria for dementia associated with Parkinson's disease. Mov Disord (2007) 22:1689-707. doi:10.1002/mds.21507

15. Beck AT, Ward CH, Mendelsohn M, Mock J, Erbaugh J. An inventory for measuring depression. Arch Gen Psychiatry (1961) 4:561-71. doi:10.1001/archpsyc. 1961.01710120031004

16. Friston KJ, Holmes AP, Worsley KJ, Poline JB, Frith CD, Frackowiak RSJ. Statistical parametric maps in functional imaging: a general approach. Hum Brain Mapp (1994) 2:189-210. doi:10.1002/hbm.460020402

17. Talairach J, Tournoux P. Co-Planar Stereotaxic Atlas of the Human Brain: An Approach to Medical Cerebral Imaging. Stuttgart, New York: Thieme (1988).

18. Friston KJ, Jezzard P, Turner R. Analysis of functional MRI time-series. Hum Brain Mapp (1994) 1:153-71. doi:10.1002/hbm.460010207

19. Friston KJ, Ashburner J, Frith CD, Poline JB, Heather JD, Frackowiak RSJ. Spatial registration and normalization of images. Hum Brain Mapp (1995) 2:165-89. doi:10.1002/hbm.460030303

20. Ungerleider LG, Haxby JV. 'What' and 'where' in the human brain. Curr Opin Neurobiol (1994) 4:157-65. doi:10.1016/0959-4388(94)90066-3

21. Benton AL, Hamsher KdeS, Varney NR, Spreen O. Contributions to Neuropsychological Assessment. 2nd ed. New York: Oxford University Press (1994).

22. Canivez GL. Incremental criterion validity of WAIS-IV factor index scores: relationships with WIAT-II and WIAT-III subtest and composite scores. Psychol Assess (2013) 25:484-95. doi:10.1037/a0032092

23. Laatu S, Revonsuo A, Pihko L, Portin R, Rinne JO. Visual object recognition deficits in early Parkinson's disease. Parkinsonism Relat Disord (2004) 10:227-33. doi:10.1016/j.parkreldis.2004.02.001

24. Ska B, Poissant A, Joanette Y. Line orientation judgment in normal elderly and subjects with dementia of Alzheimer's type. J Clin Exp Neuropsychol (1990) 12:695-702. doi:10.1080/01688639008401012

25. Wu T, Wang J, Wang C, Hallett M, Zang Y, Wu X, et al. Basal ganglia circuits changes in Parkinson's disease patients. Neurosci Lett (2012) 524:55-9. doi:10.1016/j.neulet.2012.07.012

26. Di Martino A, Scheres A, Margulies DS, Kelly AM, Uddin LQ, Shehzad Z, et al. Functional connectivity of human striatum: a resting state FMRI study. Cereb Cortex (2008) 18:2735-47. doi:10.1093/cercor/bhn041

27. Umarova RM, Saur D, Schnell S, Kaller CP, Vry MS, Glauche V, et al. Structural connectivity for visuospatial attention: significance of ventral pathways. Cereb Cortex (2010) 20:121-9. doi:10.1093/cercor/bhp086

28. Owen AM, Doyon J, Dagher A, Sadikot A, Evans AC. Abnormal basal ganglia outflow in Parkinson's disease identified with PET. Brain (1998) 121:949-65.

29. Jueptner M, Weiller C. A review of differences between basal ganglia and cerebellar control of movements as revealed by functional imaging studies. Brain (1998) 121:1437-49. doi:10.1093/brain/121.8.1437

30. Amick MM, Schendan HE, Ganis G, Cronin-Golomb A. Frontostriatal circuits are necessary for visuomotor transformation: mental rotation in Parkinson's disease. Neuropsychologia (2006) 44:339-49. doi:10.1016/j.neuropsychologia. 2005.06.002

31. MacDonald PA, MacDonald AA, Seergobin KN, Tamjeedi R, Ganjavi H, Provost JS, et al. The effect of dopamine therapy on ventral and dorsal striatum-mediated cognition in Parkinson's disease: support from functional MRI. Brain (2011) 134:1447-63. doi:10.1093/brain/awr075

32. Tang YY, Rothbart MK, Posner MI. Neural correlates of establishing, maintaining, and switching brain states. Trends Cogn Sci (2012) 16:330-7. doi:10.1016/j. tics.2012.05.001

33. Nelson SM, Cohen AL, Power JD, Wig GS, Miezin FM, Wheeler ME, et al. A parcellation scheme for human left lateral parietal cortex. Neuron (2010) 67:156-70. doi:10.1016/j.neuron.2010.05.025

34. Ebisch SJ, Mantini D, Romanelli R, Tommasi M, Perrucci MG, Romani GL, et al. Long-range functional interactions of anterior insula and medial frontal cortex are differently modulated by visuospatial and inductive reasoning tasks. Neuroimage (2013) 78:426-38. doi:10.1016/j.neuroimage.2013.04.058

35. Sridharan D, Levitin DJ, Menon V. A critical role for the right fronto-insular cortex in switching between central-executive and default-mode networks. PNAS (2008) 105:12569-74. doi:10.1073/pnas.0800005105

36. Carlesimo GA, Piras F, Assogna F, Pontieri FE, Caltagirone C, Spalletta G. Hippocampal abnormalities and memory deficits in Parkinson disease. Neurology (2012) 78:1939-45. doi:10.1212/WNL.0b013e318259e1c5

37. Nagano-Saito A, Washimi Y, Arahata Y, Kachi T, Lerch JP, Evans AC, et al. Cerebral atrophy and its relation to cognitive impairment in Parkinson disease. Neurology (2005) 64:224-9. doi:10.1212/01.WNL.0000149510.41793.50

38. Possin KL. Visual spatial cognition in neurodegenerative disease. Neurocase (2010) 16:466-87. doi:10.1080/13554791003730600

39. Calabresi P, Castrioto A, Di Filippo M, Picconi B. New experimental and clinical links between the hippocampus and the dopaminergic system in Parkinson's disease. Lancet Neurol (2013) 12:811-21. doi:10.1016/S14744422(13)70118-2

40. Iaria G, Petrides M, Dagher A, Pike B, Bohbot VD. Cognitive strategies dependent on the hippocampus and caudate nucleus in human navigation: variability and change with practice. J Neurosci (2003) 23:5945-52. doi:10.1371/journal. pone.0002949

41. Braga RM, Wilson LR, Sharp DJ, Wise RJ, Leech R. Separable networks for topdown attention to auditory non-spatial and visuospatial modalities. Neuroimage (2013) 74:77-86. doi:10.1016/j.neuroimage.2013.02.023

42. Meppelink AM, de Jong BM, Renken R, Leenders KL, Cornelissen FW, van Laar T. Impaired visual processing preceding image recognition in Parkinson's disease patients with visual hallucinations. Brain (2009) 132:2980-93. doi:10.1093/brain/awp223

43. Eslinger PJ, Blair C, Wang J, Lipovsky B, Realmuto J, Baker D, et al. Developmental shifts in $\mathrm{fMRI}$ activations during visuospatial relational reasoning. Brain Cogn (2009) 69:1-10. doi:10.1016/j.bandc.2008.04.010

44. Carbon M, Ma Y, Barnes A, Dhawan V, Chaly T, Ghilardi MF, et al. Caudate nucleus: influence of dopaminergic input on sequence learning and brain activation in Parkinsonism. Neuroimage (2004) 21:1497-507. doi:10.1016/j. neuroimage.2003.12.014

45. Carbon M, Marié RM. Functional imaging of cognition in Parkinson's disease. Curr Opin Neurol (2003) 16:475-80. doi:10.1097/01.wco.0000084225.82329.3c

46. Monchi O, Petrides M, Mejia-Constain B, Strafella AP. Cortical activity in Parkinson's disease during executive processing depends on striatal involvement. Brain (2007) 130:233-44. doi:10.1093/brain/awl326

47. Goulas A, Uylings HB, Stiers P. Unravelling the intrinsic functional organization of the human lateral frontal cortex: a parcellation scheme based on resting state fMRI. J Neurosci (2012) 32:10238-52. doi:10.1523/JNEUROSCI.5852-11. 2012

48. Wright CI, Keuthen NJ, Savage CR, Martis B, Williams D, Wedig M, et al. Brain correlates of negative and positive visuospatial priming in adults. Neuroimage (2006) 30:983-91. doi:10.1016/j.neuroimage.2005.10.015

49. Lee EY, Cowan N, Vogel EK, Rolan T, Valle-Inclán F, Hackley SA. Visual working memory deficits in patients with Parkinson's disease are due to both reduced storage capacity and impaired ability to filter out irrelevant information. Brain (2010) 133:2677-89. doi:10.1093/brain/awq197

50. Caproni S, Muti M, Principi M, Ottaviano P, Frondizi D, Capocchi G, et al. Complexity of motor sequences and cortical reorganization in Parkinson's disease: a functional MRI study. PLoS One (2013) 8:e66834. doi:10.1371/journal.pone. 0066834 
51. Richards M, Cote LJ, Stern Y. The relationship between visuospatial ability and perceptual motor function in Parkinson's disease. J Neurol Neurosurg Psychiatry (1993) 56:400-6. doi:10.1136/jnnp.56.4.400

52. Walter E, Dassonville P. Visuospatial contextual processing in the parietal cortex: an fMRI investigation of the induced Roelofs effect. Neuroimage (2008) 42:1686-97. doi:10.1016/j.neuroimage.2008.06.016

53. Walter E, Dassonville P. Activation in a frontoparietal cortical network underlies individual differences in the performance of an embedded figures task. PLoS One (2011) 6:e20742. doi:10.1371/journal.pone.0020742

54. Roser ME, Fiser J, Aslin RN, Gazzaniga MS. Right hemisphere dominance in visual statistical learning. J Cogn Neurosci (2011) 23:1088-99. doi:10.1162/jocn. 2010.21508

55. Westlye LT, Grydeland H, Walhovd KB, Fjell AM. Associations between regional cortical thickness and attentional networks as measured by the attention network test. Cereb Cortex (2011) 21:345-56. doi:10.1093/cercor/bhq101

56. Nelson SM, Dosenbach NU, Cohen AL, Wheeler ME, Schlaggar BL, Petersen SE. Role of the anterior insula in task-level control and focal attention. Brain Struct Funct (2010) 214:669-80. doi:10.1007/s00429-010-0260-2

57. Helbig HB, Ernst MO, Ricciardi E, Pietrini P, Thielscher A, Mayer KM, et al. The neural mechanisms of reliability weighted integration of shape information from vision and touch. Neuroimage (2012) 60:1063-72. doi:10.1016/j. neuroimage.2011.09.072

58. Chaves S, Vannini P, Jann K, Wurtz P, Federspiel A, Nyffeler T, et al. The link between visual exploration and neuronal activity: a multi-modal study combining eye tracking, functional magnetic resonance imaging and transcranial magnetic stimulation. Neuroimage (2012) 59:3652-61. doi:10.1016/j.neuroimage. 2011.10.094

59. Heinen K, Ruff CC, Bjoertomt O, Schenkluhn B, Bestmann S, Blankenburg F, et al. Concurrent TMS-fMRI reveals dynamic interhemispheric influences of the right parietal cortex during exogenously cued visuospatial attention. Eur J Neurosci (2011) 33:991-1000. doi:10.1111/j.1460-9568.2010.07580.x
60. Stebbins GT, Goetz CG, Carrillo MC, Bangen KJ, Turner DA, Glover GH, et al. Altered cortical visual processing in PD with hallucinations: an fMRI study. Neurology (2004) 63:1409-16. doi:10.1212/01.WNL.0000141853.27081.BD

61. Thürling M, Hautzel H, Küper M, Stefanescu MR, Maderwald S, Ladd ME, et al. Involvement of the cerebellar cortex and nuclei in verbal and visuospatial working memory: a 7 T fMRI study. Neuroimage (2012) 62:1537-50. doi:10.1016/j.neuroimage.2012.05.037

62. Sundermann B, Pfleiderer B. Functional connectivity profile of the human inferior frontal junction: involvement in a cognitive control network. BMC Neurosci (2012) 13:119. doi:10.1186/1471-2202-13-119

63. Zhang S, Li CS. Functional connectivity mapping of the human precuneus by resting state fMRI. Neuroimage (2012) 59:3548-62. doi:10.1016/j.neuroimage. 2011.11.023

Conflict of Interest Statement: The authors declare that the research was conducted in the absence of any commercial or financial relationships that could be construed as a potential conflict of interest.

Received: 20 May 2014; accepted: 25 July 2014; published online: 11 August 2014. Citation: Caproni S, Muti M, Di Renzo A, Principi M, Caputo N, Calabresi P and Tambasco N (2014) Subclinical visuospatial impairment in Parkinson's disease: the role of basal ganglia and limbic system. Front. Neurol. 5:152. doi: 10.3389/fneur.2014.00152 This article was submitted to Movement Disorders, a section of the journal Frontiers in Neurology.

Copyright (C) 2014 Caproni, Muti, Di Renzo, Principi, Caputo, Calabresi and Tambasco. This is an open-access article distributed under the terms of the Creative Commons Attribution License (CC BY). The use, distribution or reproduction in other forums is permitted, provided the original author(s) or licensor are credited and that the original publication in this journal is cited, in accordance with accepted academic practice. No use, distribution or reproduction is permitted which does not comply with these terms. 